\title{
Differential frontal-striatal and paralimbic activity during reversal learning in major depressive disorder and obsessive-compulsive disorder
}

\author{
P. L. Remijnse ${ }^{1,2 *}$, M. M. A. Nielen ${ }^{1}$, A. J. L. M. van Balkom ${ }^{1,3}$, G.-J. Hendriks ${ }^{4,5}$, W. J. Hoogendijk ${ }^{1,3}$, \\ H. B. M. Uylings ${ }^{2,6,7}$ and D. J. Veltman ${ }^{1,2,3}$ \\ ${ }^{1}$ Department of Psychiatry, VU University Medical Center, Amsterdam, The Netherlands \\ ${ }^{2}$ Graduate School Neurosciences, Amsterdam, The Netherlands \\ ${ }^{3}$ Out-patient Academic Clinic for Anxiety and Mood Disorders, GGZ Buitenamstel, Amsterdam, The Netherlands \\ ${ }^{4}$ Out-patient Clinic for Anxiety Disorders, GGZ Nijmegen, The Netherlands \\ ${ }^{5}$ Department of Psychiatry, Radboud University Nijmegen Medical Center, Nijmegen, The Netherlands \\ ${ }^{6}$ Department of Anatomy and Neuroscience, VU University Medical Center, Amsterdam, The Netherlands \\ ${ }^{7}$ School for Mental Health and Neuroscience, Department of Psychiatry and Neuropsychology, University of Maastricht, The Netherlands
}

Background. Several lines of research suggest a disturbance of reversal learning (reward and punishment processing, and affective switching) in patients with major depressive disorder (MDD). Obsessive-compulsive disorder (OCD) is also characterized by abnormal reversal learning, and is often co-morbid with MDD. However, neurobiological distinctions between the disorders are unclear. Functional neuroimaging (activation) studies comparing MDD and OCD directly are lacking.

Method. Twenty non-medicated OCD-free patients with MDD, 20 non-medicated MDD-free patients with OCD, and 27 healthy controls performed a self-paced reversal learning task in an event-related design during functional magnetic resonance imaging (fMRI).

Results. Compared with healthy controls, both MDD and OCD patients displayed prolonged mean reaction times (RTs) but normal accuracy. In MDD subjects, mean RTs were correlated with disease severity. Imaging results showed MDD-specific hyperactivity in the anterior insula during punishment processing and in the putamen during reward processing. Moreover, blood oxygen level-dependent (BOLD) responses in the dorsolateral prefrontal cortex (DLPFC) and the anterior PFC during affective switching showed a linear decrease across controls, MDD and OCD. Finally, the OCD group showed blunted responsiveness of the orbitofrontal (OFC)-striatal loop during reward, and in the OFC and anterior insula during affective switching.

Conclusions. This study shows frontal-striatal and (para)limbic functional abnormalities during reversal learning in MDD, in the context of generic psychomotor slowing. These data converge with currently influential models on the neuropathophysiology of MDD. Moreover, this study reports differential neural patterns in frontal-striatal and paralimbic structures on this task between MDD and OCD, confirming previous findings regarding the neural correlates of deficient reversal learning in OCD.

Received 1 February 2008; Revised 15 September 2008; Accepted 4 December 2008; First published online 27 January 2009

Key words: Functional MRI, major depressive disorder, obsessive-compulsive disorder, orbitofrontal cortex, reversal learning.

\section{Introduction}

Reversal learning is a neuropsychological function crucial for socio-emotional learning and behavior in primates (Rolls, 1999). It is defined as the ability to associate neutral stimuli with their rewarding or punishing values, and to alter these associations upon

* Address for correspondence: P. L. Remijnse, M.D., VU University Medical Center, Department of Anatomy and Neurosciences, room G102B, Van der Boechorststraat 7, 1081 BT Amsterdam, The Netherlands.

(Email : PL.Remijnse@vumc.nl) reversing reinforcement contingencies (Dias et al. 1996; Rolls, 1999). Several lines of evidence indicate that reversal learning (also termed affective switching) is disturbed in major depressive disorder (MDD), at a clinical, behavioral and neural level.

Clinically, MDD is by definition characterized by 'anhedonia' (APA, 1994) and patients with MDD experience a negative thought bias (Beck, 1963). Neurocognitive studies have reported aberrant responding to reward and punishment feedback in depressed patients (Henriques et al. 1994; Elliott et al. 1996; Must et al. 2006), and also a reduced ability to 
exert inhibitory control during an affective switching (go/no-go) task (Murphy et al. 1999). At a neurochemical level, there is abundant evidence that the pathophysiology of MDD is characterized by underlying dysfunctional serotonin [5-hydroxytryptamine (5-HT)] transmission (Mann et al. 1996), and various manipulations of 5-HT neurotransmission in human volunteers (Rogers et al. 1999; Chamberlain et al. 2006) have induced impaired performance on two-choice discrimination reversal tasks. For instance, acute tryptophan depletion (ATD) has been shown to affect reversal learning in healthy subjects (Murphy et al. 2002; Evers et al. 2005), and to induce a temporary relapse of depressive symptoms in recovered patients with MDD (Smith et al. 1997).

Finally, lesion and neuroimaging studies in nonhuman and human primates have implicated the orbitofrontal (OFC)-striatal circuit in reversal learning (Dias et al. 1996; Fellows \& Farah, 2003; Clark et al. 2004), which is one of the brain's parallel frontalstriatal circuits supposedly involved in the pathophysiology of MDD (Alexander et al. 1990; Rogers et al. 2004). However, recent neuroimaging work has shown the engagement of additional frontal cortical brain areas in reversal learning, in particular the dorsolateral prefrontal cortex (DLPFC), anterior PFC, anterior insula, and anterior cingulate cortex (ACC) (Remijnse et al. 2005a ; Budhani et al. 2006); that is, regions also implicated in MDD (Drevets, 2000; Phillips et al. 2003; Mitterschiffthaler et al. 2006).

Taken together, these findings suggest that performance of reversal learning may be impaired in MDD, associated with functional abnormalities in frontal-striatal and (para)limbic brain regions. To date, one neuropsychological study has reported a preserved ability to acquire and reverse a probabilistic discrimination, but an incapacity for depressed patients to maintain response set in the face of misleading negative feedback after having attained criterion for successful discrimination (Murphy et al. 2003).

Obsessive-compulsive disorder (OCD) is frequently a co-morbid disorder with MDD (Overbeek et al. 2002) and shares several features with MDD, including symptomatic overlap (Ninan \& Berger, 2001) and clinical improvement following serotonergic antidepressants (Levine et al. 2001). However, MDD and OCD differ with respect to core clinical symptoms and neuropsychological profiles (Purcell et al. 1998; Joel et al. 2005). Ideally, identification of shared and distinct neural substrates for MDD and OCD may lead to a biologically grounded distinction between these disorders (Chamberlain et al. 2005; Chamberlain \& Sahakian, 2006). We know of only two neuroimaging studies comparing these two disorders directly (Edmonstone et al. 1994; Saxena et al. 2001), demonstrating increased activity in the bilateral putamen but diminished activity in the left hippocampus (for MDD versus OCD) during the resting state. To date, neuroimaging activation studies using cognitive or mixed cognitive/emotional paradigms in MDD and OCD have not yielded consistent findings regarding differential involvement of brain areas in these disorders (Drevets, 2000; Phillips et al. 2003; Remijnse et al. 2005b), and comparative studies in this field are lacking.

We have recently published studies on the neural correlates of reversal learning in a group of healthy volunteers (Remijnse et al. 2005a) and also in comparison with a sample of OCD patients (Remijnse et al. 2006). The aim of the present study was twofold: first, we sought to explore the neural correlates of reversal learning using functional magnetic resonance imaging (fMRI) in a sample of unmedicated patients with MDD, compared with our healthy control group that has been described before (Remijnse et al. 2005a). Based on existing neuropsychological and neuroimaging data, we hypothesized impaired performance in the patient group, associated with abnormal OFCstriatal (Fellows \& Farah, 2003; Clark et al. 2004), DLPFC and anterior PFC, ACC and insular activations (Remijnse et al. 2005a; Budhani et al. 2006). Second, we aimed to compare MDD and OCD directly in a single activation design. We recently demonstrated impaired reversal learning in OCD, associated with abnormal OFC-striatal, DLPFC, anterior PFC and anterior insular activity compared with healthy controls (Remijnse et al. 2006). However, as this previous OCD sample included patients with co-morbid depression, we assembled a new group of MDD-free, unmedicated OCD patients for the current study. Based on the sparse direct-comparison neuroimaging literature (Edmonstone et al. 1994), we hypothesized that patients with MDD may show increased putamen activity, compared with OCD patients.

\section{Method}

\section{Subjects}

Twenty patients with OCD-free MDD, 20 patients with OCD and currently (but not lifetime) free of MDD, and 27 healthy controls participated in this study (Table 1). The current OCD group consisted of 13 MDD-free OCD patients that also participated in our previous study (Remijnse et al. 2006), and seven newly recruited patients. Diagnoses and co-morbidity were established by experienced clinicians with the Structured Clinical Interview for DSM-IV Axis-I disorders (SCID; First et al. 1996). Exclusion criteria were the presence of alcohol or substance abuse at the time 
Table 1. Demographic and clinical data for patients with major depressive disorder (MDD), patients with obsessive-compulsive disorder (OCD), and for the healthy control group

\begin{tabular}{|c|c|c|c|c|}
\hline & $\operatorname{MDD}(n=20)$ & OCD $(n=20)$ & Controls $(n=27)$ & $\begin{array}{l}\text { Between-groups } \\
\text { comparison } p \text { value }\end{array}$ \\
\hline Sex (female/male) & $8 / 12$ & $15 / 5$ & $19 / 8$ & $0.04^{*}$ \\
\hline Age in years (range) & $35(21-54)$ & $34(19-54)$ & $32(22-53)$ & $0.64 \dagger$ \\
\hline Handedness (R/L) & $16 / 4$ & $17 / 3$ & $23 / 4$ & $0.87^{*}$ \\
\hline $\begin{array}{l}\text { Education (range 1-10)a, } \\
\text { mean (s.D.) }\end{array}$ & $8.0(2.1)$ & $8.5(1.1)$ & $8.6(1.4)$ & $0.41 \dagger$ \\
\hline $\begin{array}{l}\text { Total YBOCS severity score, } \\
\text { mean (S.D.), range }\end{array}$ & & $22.2(5.1), 11-31$ & & \\
\hline $\begin{array}{l}\text { Number of OCD patients } \\
\text { with prior MDD/mean } \\
\text { length in months since } \\
\text { remission of MDD }\end{array}$ & & $8 / 36$ & & \\
\hline Padua-IR, mean (S.D.) & $42.4(32.5)^{\mathrm{b}}$ & $59.7(27.8)^{\mathrm{b}}$ & $11.5(10.4)$ & $\begin{array}{l}<0.001 \dagger \\
\mathrm{MDD}=\mathrm{OCD}>\mathrm{CO} \ddagger\end{array}$ \\
\hline BDI, mean (S.D.) & $25.6(7.6)^{\mathrm{b}}$ & $12.2(7.7)^{\mathrm{c}}$ & $1.7(2.6)$ & $\begin{array}{l}<0.001 \dagger \\
\mathrm{MDD}>\mathrm{OCD}>\mathrm{CO} \ddagger\end{array}$ \\
\hline HAMD-17, mean (S.D.) & $19.1(4.1)$ & $6.9(4.0)^{\mathrm{d}}$ & $0.4(0.9)$ & $\begin{array}{l}<0.001 \dagger \\
\mathrm{MDD}>\mathrm{OCD}>\mathrm{CO} \ddagger\end{array}$ \\
\hline MADRS, mean (S.D.) & $29.7(4.7)$ & $9.1(6.5)^{b}$ & $0.6(0.9)$ & $\begin{array}{l}<0.001 \dagger \\
\mathrm{MDD}>\mathrm{OCD}>\mathrm{CO} \uparrow\end{array}$ \\
\hline HAMA, mean (S.D.) & $19.9(5.0)^{\mathrm{b}}$ & & & \\
\hline
\end{tabular}

Y-BOCS, Yale-Brown Obsessive-Compulsive Scale; Padua-IR, Padua Inventory Revised; BDI, Beck Depression Inventory; HAMD-17, 17-item Hamilton Depression Rating Scale; HAMA, Hamilton Anxiety Rating Scale; MADRS, Montgomery-Asberg Depression Rating Scale ; CO, controls; S.D., standard deviation.

a 1 denotes primary school unfinished, 10 denotes university graduated. ${ }^{\mathrm{b}}$ Assessed in 18 patients. ${ }^{\mathrm{c}}$ Assessed in 17 patients. d Assessed in 15 patients.

${ }^{*} \chi^{2}$ test. $\dagger$ Analysis of variance (ANOVA). $\$$ Post-hoc Tukey and Scheffe tests: $p<0.05$.

of study, and major internal or neurological disorders. In the MDD group, co-morbidity was as follows: social anxiety disorder $(n=3)$, generalized anxiety disorder $(n=1)$, panic disorder without agoraphobia $(n=1)$, pain disorder $(n=1)$, and cannabis abuse in early $(n=1)$ and sustained $(n=1)$ full remission. Twelve patients were free from co-morbidity, and six patients had their first lifetime depressive episode.

In the OCD group, nine patients were diagnosed with 'pure' OCD and the following disorders were comorbid: post-traumatic stress disorder $(n=1)$, panic disorder $(n=2)$, generalized anxiety disorder $(n=4)$, dysthymic disorder $(n=4)$, social anxiety disorder $(n=4)$, and opioid abuse in sustained full remission $(n=1)$. Co-morbid Tourette disorder was clinically diagnosed in one patient. The mean duration of illness was 19.9 years in this group. At the time of the study, all patients and control subjects were free from psychotropic medication for at least 2 weeks, and in case of fluoxetine or antipsychotic medication for at least 1 month. Eight patients in the MDD group and seven patients in the OCD group were medication naïve, and the mean length of drug-free interval was 16 months in the MDD sample and 30 months in the OCD group. All participants gave written informed consent and the study was approved by the ethical review board of the VU University Medical Center.

To assess symptom characteristics and severity scores, the Yale-Brown Obsessive-Compulsive Scale (YBOCS; Goodman et al. 1989) was administered in OCD patients only, and the Padua Inventory Revised (Padua-IR; Sanavio, 1988) was used to measure all participants' obsessive-compulsive (OC) characteristics. To rate the presence and severity of depressive symptoms in all three groups, the Beck Depression Inventory (BDI; Beck et al. 1961), the 17-item Hamilton Depression Rating Scale (HAMD-17; Hamilton, 1967) and the 10-item Montgomery-Asberg Depression Rating Scale (MADRS; Montgomery \& Asberg, 1979) were used. The Hamilton Anxiety Rating Scale (HAMA; Hamilton, 1959) was administered in MDD patients only. Because of logistic problems in the patient groups, five patients with OCD failed to be interviewed with the HAMD-17 or with the MADRS $(n=2)$, and two MDD patients failed to be interviewed with the HAMA. 


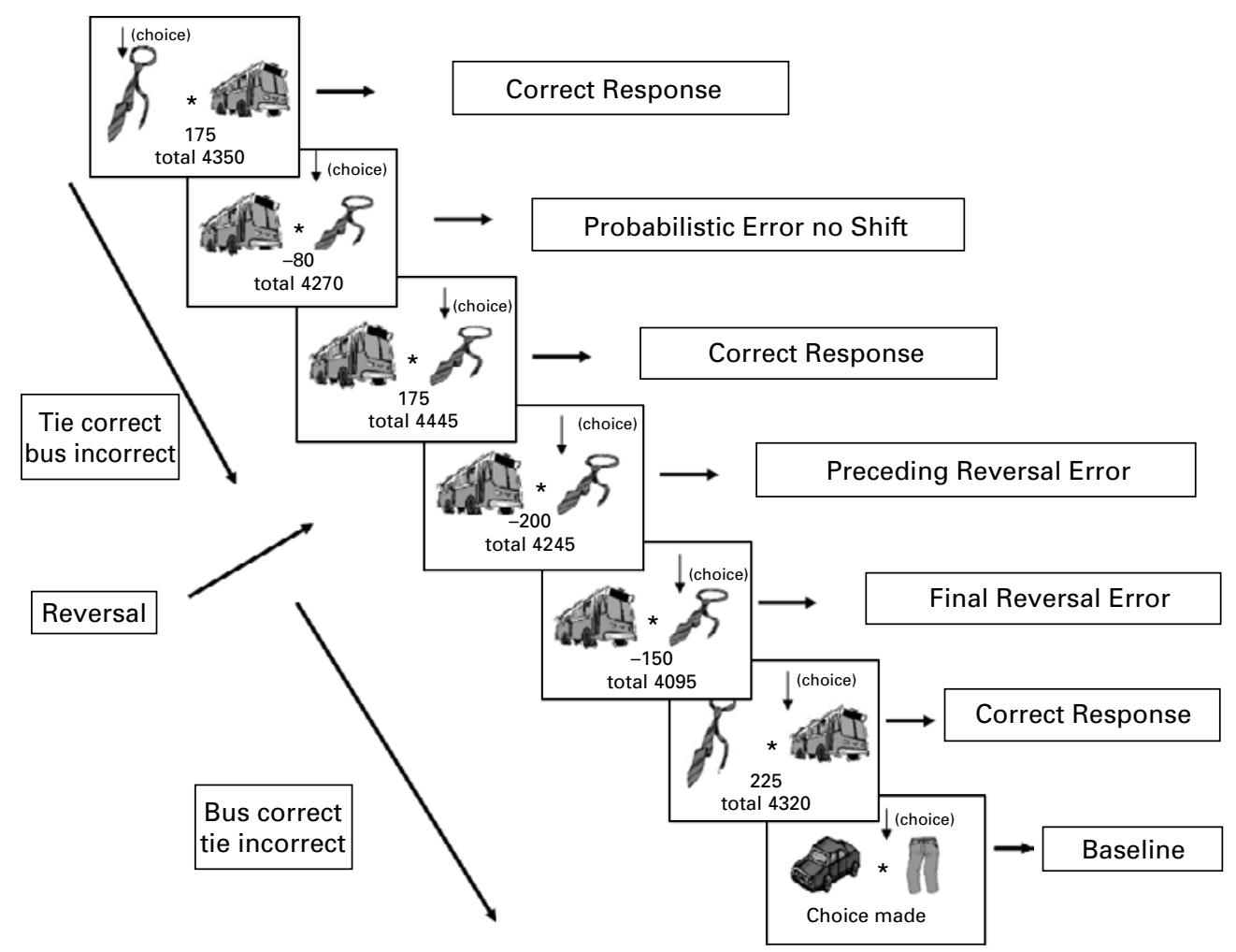

Fig. 1. The reversal learning task. In this example (consecutive trials are running from top-left to bottom-right) all events of interest are displayed. See Method section for details.

Two OCD patients and two MDD patients did not return the Padua-IR questionnaire. Three OCD patients and two MDD patients did not return the selfreport $\mathrm{BDI}$.

\section{Reversal learning task and experimental procedure}

We used a self-paced, probabilistic reversal learning task with an affectively neutral baseline (Fig. 1) that has been described previously (Remijnse et al. 2005a). Each trial in the experimental task consisted of two stimuli (a cartoon of a bus and a tie) presented at either side of a screen with randomized locations, for $3000 \mathrm{~ms}$ maximally. Subjects selected either stimulus by pressing the left or right button on a button box. Each trial ended with the presentation of positive or negative feedback in the form of a $2000 \mathrm{~ms}$ display of the number of points won or lost in that trial and the amount of accumulated points in the task up to that trial. This was followed by a fixation cross for $1000 \mathrm{~ms}$.

Upon a correct response, either positive or negative feedback was given based on an 80:20 ratio, consisting of gaining or losing a random amount of 80-250 points. A correct response with a reward outcome was defined as a 'Correct Response'. A correct response that was probabilistically given negative feedback ('Probabilistic Error') could either lead to a shift in stimulus selection ('Probabilistic Error with Shift') or not lead to such a shift ('Probabilistic Error no Shift'). The chance of a second, consecutive Probabilistic Error was 1:10 after a first Probabilistic Error. False responses ('Spontaneous Errors') were always given negative feedback. The criterion for reversal was reached after 6-10 correct responses (randomized). Immediately after reversal (unknown to the subject), a false response (according to the new criterion) not leading to a shift to the new correct stimulus was designated a Preceding Reversal Error, and the last false response prior to a shift a Final Reversal Error.

Affectively neutral baseline trials consisting of two different, equivalent stimuli (the cartoon of a car and a pair of trousers) were randomly presented interspersed with every seventh experimental trial on average. Baseline trials were never presented more than once consecutively, and put a minimal load on working memory (subjects were instructed in advance which of the two baseline stimuli to select), thus minimizing possible interference effects. Responses in this baseline task were given neutral feedback (' choice made') for $2000 \mathrm{~ms}$, followed by a fixation cross for $1000 \mathrm{~ms}$. The scanning session ended after 400 trials (including baseline trials) and lasted about $25 \mathrm{~min}$. After the scanning session, participants received the total amount of accumulated points during the task divided by 1000 in euros. 


\section{Imaging procedure}

Imaging data were collected using a 1.5-T Sonata MR system (Siemens, Erlangen, Germany) with a standard receiver head coil. Task stimuli were projected onto a screen at the end of the scanner table, visible through a mirror mounted above the subject's head. Two magnet-compatible response boxes were used to record the subject's responses.

T2*-weighted echo-planar images (EPIs) with blood oxygen level-dependent (BOLD) contrast were acquired. A customized EPI sequence sensitive to the OFC signal was used (Deichmann et al. 2003; Remijnse et al. 2006). The acquisition plane was tilted parallel to the air-tissue interface of the OFC for each subject $\left(0-15^{\circ}\right.$ from the anterior-posterior commissure line). Using this sequence with a repetition time of $2.18 \mathrm{~s}$ and an echo time of $45 \mathrm{~ms}, 35$ slices $(3 \times 3 \mathrm{~mm}$ in-plane resolution; $2.5 \mathrm{~mm}$ slice thickness; matrix size $64 \times 64$ ) were obtained.

\section{Data analysis}

Demographic and behavioral data were analyzed using SPSS version 11.5 for Windows (SPSS Inc., Chicago, IL, USA). For behavioral analysis, we assessed the mean number of baseline trials, Correct Responses, Probabilistic Errors no Shift, Final Reversal Errors, Preceding Reversal Errors, Probabilistic Errors with Shift, and Spontaneous Errors, the mean reaction times (RTs) for these events and the number of points accumulated by the end of the task. Performance differences between groups were assessed by one-way analyses of variance (ANOVAs) with Group (MDD versus OCD versus controls) as the between-subject factor and Event Type as the within-subject factor. In addition, correlations were calculated between performance measures and depression or OC severity measures for the MDD and the OCD group respectively.

Imaging analysis was performed using SPM2 (Statistical Parametric Mapping; Wellcome Department of Cognitive Neurology, London, UK). Images were reoriented, slice-timed and realigned to the first volume. The resulting mean image was then coregistered with the whole-brain EPI volume, and images were normalized to MNI space as defined by an SPM T2* template and spatially smoothed using a $6 \mathrm{~mm}$ full-width at half-maximum (FWHM) Gaussian kernel. Statistical analysis was carried out in the context of the general linear model, in which each event was modeled using a delta function convolved with the canonical hemodynamic response function (HRF). The following events were modeled to the onset of the feedback presentation, as defined previously: (1) baseline events, (2) Correct Responses, (3) Probabilistic
Errors no Shift, (4) Preceding Reversal Errors, and (5) Final Reversal Errors. Two events were modelled as events of no interest: (6) Spontaneous Errors and (7) Probabilistic Errors with Shift. We excluded the latter from analysis because these were regarded as part of a subject's trial-and-error strategy instead of capturing a genuine set shift in stimulus-reinforcement associations. Movement parameters were included in the model as regressors of no interest.

The following contrasts were computed: (1) Correct Responses minus baseline trials to assess the main effect of reward, (2) Probabilistic Errors no Shift + Preceding Reversal Errors+Final Reversal Errors minus baseline trials to assess the main effect of all punishment events, and (3) Final Reversal Errors minus (Probabilistic Errors no Shift + Preceding Reversal Errors) to subtract punishment events not leading to a shift from punishment events prior to a shift, to isolate affective switching (Remijnse et al. 2005a). Contrasts (1) and (2) involved the affectively neutral baseline to assess the neural substrate of the main effect of reward and punishment respectively. This ensured that general aspects of motivational processing were not left undetected.

Contrasts were first performed at single-subject level. These were then entered into a second-level (random effects) analysis by calculating one-sample $t$ tests on each individual's contrast images for contrasts 1-3. Group main effects for each contrast (Appendix A) were analyzed with one-way ANOVA. Next, we performed Group $\times$ Task interaction analyses for our contrasts of interest. Group main effects were adjusted for the whole-brain search volume using the false discovery rate (FDR) method implemented in SPM2 (Genovese et al. 2002), and reported at a significance level of $p<0.05$. Interaction effects, masked with the relevant main effect, were reported at $p<0.001$ uncorrected for multiple comparisons, or at a slightly lower threshold for regions of a priori interest as mentioned in the introduction ( $p<0.005$ uncorrected).

\section{Results}

\section{Demographic and clinical data}

The three groups were adequately matched for age, handedness and education level, but not gender (Table 1). A one-way between-groups ANOVA showed main effects for all depression symptom severity measures (BDI, HAMD-17 and MADRS), which was due to MDD patients scoring significantly higher than OCD patients, and OCD patients significantly higher than controls. On the Padua-IR, a one-way between-groups ANOVA revealed a main effect due to both patient groups scoring higher than controls. 
A subsequent analysis of Padua-IR scores in the MDD group demonstrated that these were related to the rumination $(n=14)$, precision $(n=1)$, checking $(n=2)$ and impulses $(n=1)$ subdimensions (van Oppen et al. 1995).

\section{Behavioral data}

A one-way ANOVA showed performance differences across groups for mean RTs on baseline trials $[F(2,64)=4.6, p<0.05]$, Correct Responses $[F(2,64)=$ $4.8, p<0.02]$, Probabilistic Errors no Shift $[F(2,64)=$ $3.4, p<0.04]$, Preceding Reversal Errors $[F(2,64)=4.0$, $p<0.03]$ and Probabilistic Errors with Shift $[F(2,64)=$ 6.2, $p<0.004$ ] (Table 2). Paired comparisons showed significant RT differences between patients with MDD and healthy controls on baseline trials (independent samples $t$ test: $t=-2.9, p<0.005)$ and Preceding Reversal Errors $(t=-2.2, p<0.04)$; and between patients with OCD and controls on baseline trials $(t=$ $-2.2, p<0.05)$, Correct Responses $(t=-3.1, p<0.003)$, Probabilistic Errors no Shift $(t=-2.6, p<0.02)$, Preceding Reversal Errors $(t=-2.9, p<0.005)$ and Probabilistic Errors with Shift $(t=-3.5, p<0.001)$; but not between MDD and OCD patients. Furthermore, in the MDD group, we found significant positive correlations between mean RTs and depression severity measures (MADRS, HAMD-17 and BDI) for Correct Responses, Probabilistic Errors no Shift, Final Reversal Errors, Preceding Reversal Errors, Spontaneous Errors and Probabilistic Errors with Shift (correlations ranging between $r=0.44$ and $r=0.62$; all $p<0.05$ ). No significant correlations were detected between mean RTs and OC severity scores in the OCD sample.

One-way ANOVA did not reveal significant performance differences across groups for mean numbers of events or points accumulated by the end of the task.

There were no significant correlations between mean numbers of events and depression severity measures in the MDD group, or OC severity measures in the OCD group, except for a negative correlation between mean number of Spontaneous Errors and YBOCS scores $(r=-0.46, p<0.04)$.

\section{Imaging data}

Reward

Between-group interaction analyses (Table 3) demonstrated increased activity in MDD patients compared with healthy controls in the left gyrus precentralis, right superior temporal and occipital cortex, and the left putamen. Comparing MDD patients with OCD patients, MDD patients showed increased activity in the right medial OFC, right superior temporal cortex, left occipital cortex and right putamen.

\section{Punishment}

Interaction analyses (Table 3) demonstrated increased activity in the left insular cortex and right precuneus in MDD patients versus healthy controls. Betweenpatient group comparisons showed left insular cortex hyperactivity for MDD versus OCD patients, but no activations for OCD versus MDD patients.

\section{Affective switching}

Interaction analyses (Table 3) showed greater activation in the left anterior PFC, right DLPFC, left ACC, right insula, left inferior parietal cortex and right thalamus in healthy controls versus patients with MDD (Fig. 2). The reverse contrast (MDD > controls) showed an increased BOLD signal in the right inferior parietal and the left superior parietal cortex. When comparing MDD and OCD patients directly, we found activation in the left anterior PFC, right DLPFC, left insula, bilateral superior temporal and left superior parietal cortex for MDD > OCD (Fig. 2), but no activity for $\mathrm{OCD}>\mathrm{MDD}$.

\section{Discussion}

The present study on reversal learning revealed mean RT differences across two groups of unmedicated patients with either MDD or OCD, and a sample of healthy controls. Patients with MDD were significantly slower to respond on baseline trials and Preceding Reversal Errors compared with normal controls, and there were significant positive correlations between mean RTs and depression severity measures for most event categories in the MDD group. These observations are in line with findings that MDD affects psychomotor reaction speed (Kalb et al. 2006). We found no differences in mean numbers of experimental events or accumulated points between MDD patients and controls. This finding seems to be in accordance with Murphy et al. (2003), who reported preserved ability to learn stimulus-reinforcement associations and to perform affective switching in medicated MDD patients. However, these authors also reported an increased tendency for depressed patients to switch response following misleading negative feedback, a cognitive measure roughly equivalent to the number of Probabilistic Errors with Shift in our task. We failed to replicate this finding, possibly because of major differences in task implementation between studies; for example, our experimental design, compared with Murphy et al. (2003), comprised a fivefold larger total number of trials (400 v. 80), implemented many versus only two reversal stages, and included no probabilistic positive reinforcement to incorrect stimuli. 
Table 2. Behavioral data on the reversal learning task for the group of patients with major depressive disorder (MDD), with obsessive-compulsive disorder (OCD), and for the healthy control group

\begin{tabular}{|c|c|c|c|c|c|c|c|c|}
\hline \multirow[b]{2}{*}{ Event type } & \multicolumn{2}{|c|}{$\operatorname{MDD}(n=20)$} & \multicolumn{2}{|c|}{$\operatorname{OCD}(n=20)$} & \multicolumn{2}{|c|}{ Controls $(n=27)$} & \multirow{2}{*}{$\begin{array}{l}\text { Group } \times \text { Event Type } \\
\text { for mean numbers } \\
(\text { ANOVA) } \\
F \text { value } \\
d f=2,64\end{array}$} & \multirow{2}{*}{$\begin{array}{l}\text { Group } \times \text { Event Type } \\
\text { for mean RTs } \\
\text { (ANOVA) } \\
F \text { value } \\
\mathrm{df}=2,64\end{array}$} \\
\hline & $\begin{array}{l}\text { Mean } \\
\text { number } \\
\text { (S.D.) }\end{array}$ & $\begin{array}{l}\text { Mean } \\
\text { RT } \\
\text { (s.D.) }\end{array}$ & $\begin{array}{l}\text { Mean } \\
\text { number } \\
\text { (s.D.) }\end{array}$ & $\begin{array}{l}\text { Mean } \\
\text { RT } \\
\text { (s.D.) }\end{array}$ & $\begin{array}{l}\text { Mean } \\
\text { number } \\
\text { (s.D.) }\end{array}$ & $\begin{array}{l}\text { Mean } \\
\text { RT } \\
\text { (s.D.) }\end{array}$ & & \\
\hline Baseline trials & $47(2.4)$ & $0.86(0.18)$ & $46(3.1)$ & $0.82(0.16)$ & $47(3.5)$ & $0.73(0.13)$ & 0.9 N.S. & $\begin{array}{l}4.6^{*} \\
\mathrm{OCD}>\mathrm{CO} \dagger \\
\mathrm{MDD}>\mathrm{CO} \dagger\end{array}$ \\
\hline Correct Responses & $224(24.8)$ & $0.66(0.15)$ & $224(23.2)$ & $0.73(0.18)$ & $224(17.1)$ & $0.59(0.12)$ & 0.01 N.s. & $\begin{array}{l}4.8^{*} \\
\mathrm{OCD}>\mathrm{CO} \dagger\end{array}$ \\
\hline Probabilistic Errors no Shift & $18(4.6)$ & $0.64(0.16)$ & $19(7.6)$ & $0.69(0.18)$ & $19(7.7)$ & $0.57(0.13)$ & 0.24 N.s. & $\begin{array}{l}3.4^{*} \\
\mathrm{OCD}>\mathrm{CO} \dagger\end{array}$ \\
\hline Final Reversal Errors & $17(5.3)$ & $0.67(0.18)$ & $16(5.2)$ & $0.72(0.23)$ & $17(5.8)$ & $0.60(0.14)$ & 0.17 N.S. & 2.5 N.S. \\
\hline Preceding Reversal Errors & $17(11.0)$ & $0.65(0.19)$ & $15(10.5)$ & $0.68(0.19)$ & $16(9.4)$ & $0.56(0.89)$ & 0.22 N.s. & $\begin{array}{l}4.0^{*} \\
\mathrm{OCD}^{\prime}>\mathrm{CO}^{\dagger} \\
\mathrm{MDD}>\mathrm{CO}^{\dagger}\end{array}$ \\
\hline Spontaneous Errors & $54(29.2)$ & $0.77(0.16)$ & $59(25.3)$ & $0.82(0.20)$ & $55(23.1)$ & $0.71(0.19)$ & 0.19 N.S. & 2.1 N.s. \\
\hline Probabilistic Errors with Shift & $22(7.0)$ & $0.66(0.16)$ & $21(8.0)$ & $0.76(0.18)$ & $21(8.2)$ & $0.60(0.13)$ & 0.07 N.s. & $\begin{array}{l}6.2^{* *} \\
\mathrm{OCD}>\mathrm{CO} \dagger\end{array}$ \\
\hline $\begin{array}{l}\text { Number of accumulated points } \\
\text { by end of task }\end{array}$ & $\begin{array}{l}15659 \\
(8195)\end{array}$ & & $\begin{array}{l}15228 \\
(7561)\end{array}$ & & $\begin{array}{l}15524 \\
(5998)\end{array}$ & & 0.02 N.s. & \\
\hline
\end{tabular}

ANOVA, analysis of variance; df, degrees of freedom; N.S., not significant; RTs, reaction times ; CO, controls; S.D., standard deviation.

${ }^{*} p<0.05,{ }^{* *} p<0.005$. $\dagger$ Paired-comparison $t$ tests: $p<0.05$; see text for further between-group details. 
Table 3. Brain regions showing group interaction effects for reward (Correct Responses minus baseline trials), punishment [(Probabilistic Errors no Shift + Final Reversal Errors + Preceding Reversal Errors) minus baseline trials] and affective switching [Final Reversal Errors minus (Preceding Reversal Errors + Probabilistic Errors no Shift)]

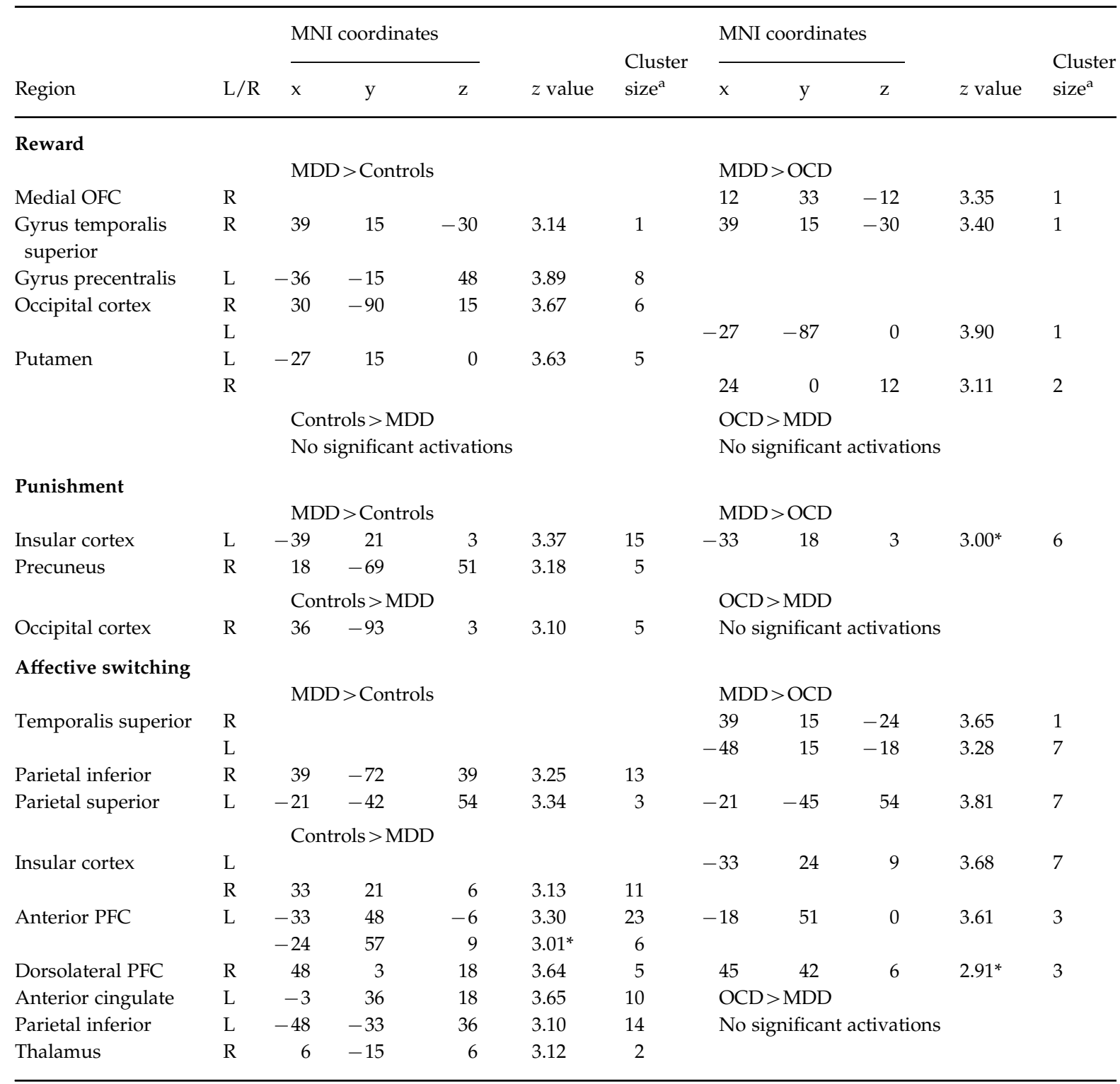

L, Left; R, right; MNI, Montreal Neurological Institute ; MDD, major depressive disorder ; OCD, obsessive-compulsive disorder; OFC, orbitofrontal cortex; PFC, prefrontal cortex.

All activations at $p<0.001$ uncorrected, except for $z$ values ${ }^{*}(p<0.005)$.

${ }^{a}$ Number of voxels.

In addition to these findings in the MDD group, patients with OCD performed slower during baseline trials, Correct Responses, Probabilistic Errors no Shift, Preceding Reversal Errors, and Probabilistic Errors with Shift, compared with healthy controls. This observation corroborates an earlier statement that slowness in OCD may be most apparent on executive tests requiring self-initiated organizational strategies, consistent with frontal-striatal abnormality (Roth et al. 2004). However, there were no significant differences in mean numbers of events or accumulated points for OCD subjects compared with the control group. This latter observation is at odds with an earlier study from our group using the same paradigm in a partially different sample of patients with OCD (Remijnse et al. 2006). This discrepancy may be due to differences in OCD patient characteristics: first, the current sample was free of co-morbid MDD and contained more patients having 'pure' OCD compared with our prior sample ( $45 \%$ v. $25 \%)$. Second, the groups differed with 
Controls > OCD
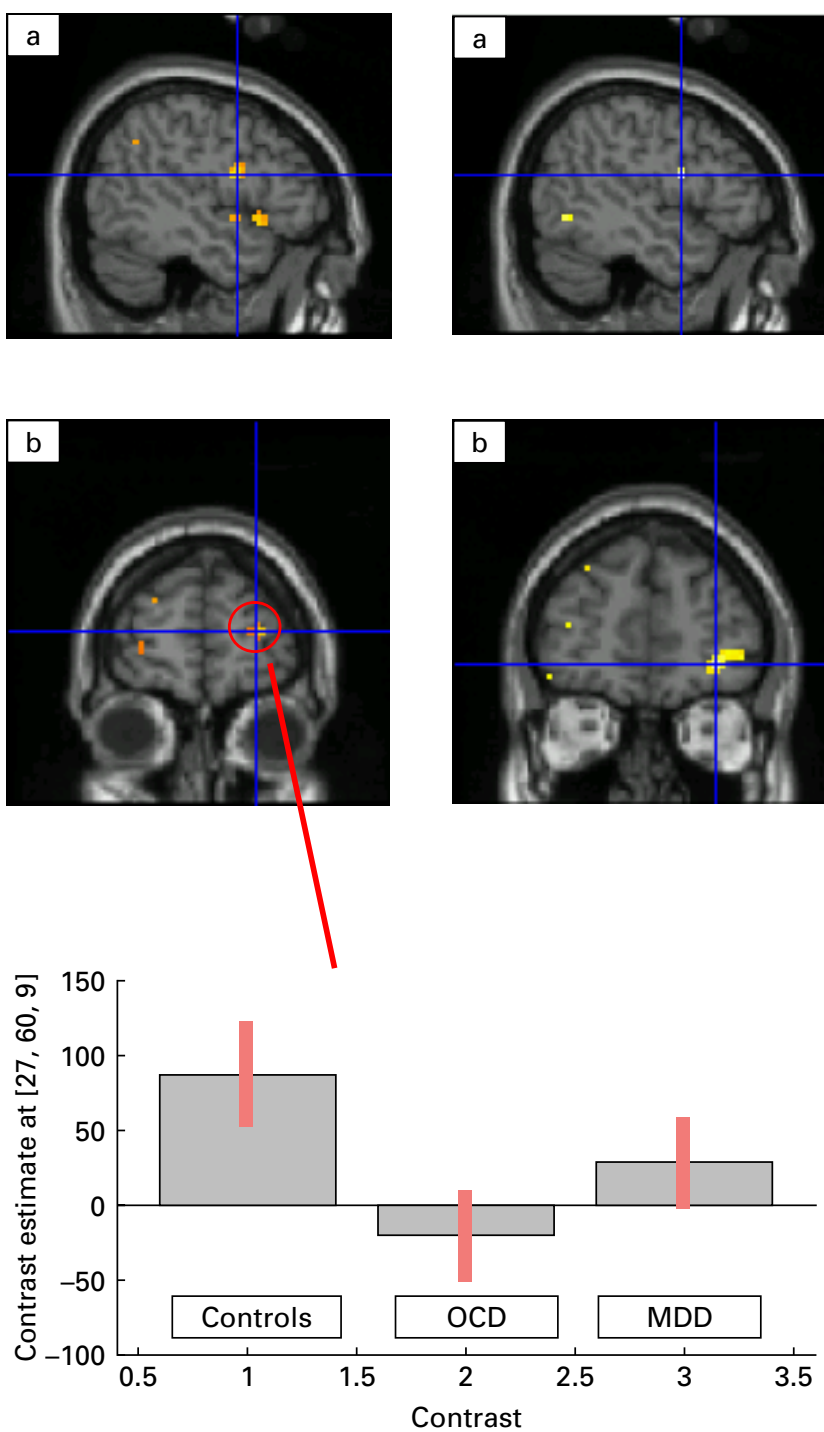
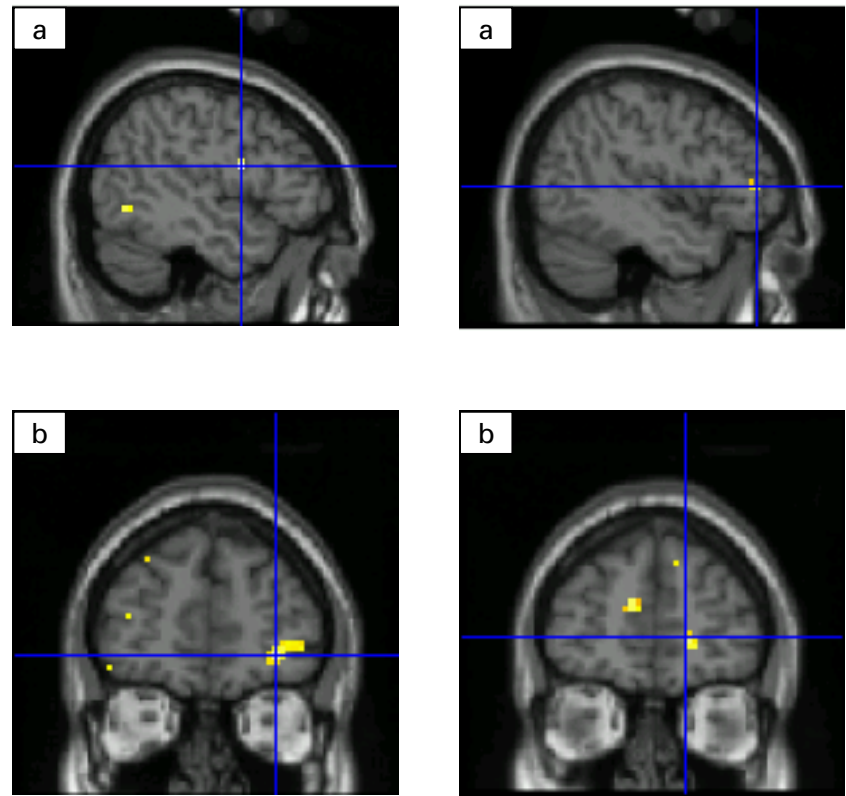

Fig. 2. Across-group interaction effects for affective switching, superimposed on sagittal and transaxial slices from a canonical [Montreal Neurological Institute (MNI) compatible] T1 image as supplied by SPM2. Increasing blood oxygen level-dependent (BOLD) responses for patients with obsessive-compulsive disorder (OCD), major depressive disorder (MDD) and healthy controls respectively are shown in (a) the right dorsolateral prefrontal cortex (DLPFC) (upper left: $\mathrm{x}=48, \mathrm{y}=3, \mathrm{z}=18$; upper middle: $\mathrm{x}=48, \mathrm{y}=3, \mathrm{z}=18$; upper right: $\mathrm{x}=45, \mathrm{y}=42, \mathrm{z}=6$ ) and $(b)$ the left anterior PFC (lower left: $\mathrm{x}=-27, \mathrm{y}=60, \mathrm{z}=9$; lower middle: $x=-33, y=48, z=-6$; lower right: $x=-18, y=51, z=0)$. A plot of effect size in the left anterior PFC is displayed for all three groups $(x=-27, y=60, z=9)$.

regard to symptom subdimensions (the ratio checkers/non-checkers was smaller in the present sample compared with the former; data not shown).

With regard to the imaging results, we found that patients with MDD exhibited increased activity in the left insula on punishment, compared to both healthy control subjects and patients with OCD (the latter at a slightly lower statistical threshold; Table 3). In MDD, neuroimaging activation studies using affective paradigms have reported increased insular responsiveness during presentation of negative stimuli in MDD (Fu et al. 2004; Anand et al. 2005; Keedwell et al. 2005). A recent model on the neuropathophysiology of depressive disorder postulates that the insula, together with the amygdala, may be the neurobiological substrate of an increased tendency to identify stimuli as emotional, and to experience predominantly negative affective states (Phillips et al. 2003). The current 
finding of punishment-related anterior insular hyperactivity in patients with MDD, in corroboration with prior imaging studies, lends support to this model. In addition, it extends previous findings by showing that this assumed role of the anterior insula is specific to depression (at least with respect to OCD).

In addition to the MDD-specific insular hyperactivity on punishment, during reward events depressed patients recruited the putamen to a greater extent than healthy controls and patients with OCD. This latter finding is in line with our between-patient group hypothesis as outlined in the introduction section. The putamen has recently been demonstrated to be involved in stimulus-action-reward associations (Haruno \& Kawato, 2006). Our finding of putamen hyperactivity upon reward is consistent with two previous imaging activation paradigms using positive valence stimuli in MDD (Kumari et al. 2003; Mitterschiffthaler et al. 2003), but it is in contrast with two other studies (Surguladze et al. 2005; Epstein et al. 2006). Differences in the nature of hedonic stimuli presented (i.e. positive words, happy faces, positive valence picture-caption pairs, or monetary reward) may account for these inconsistent results across studies. Further research is therefore warranted to clarify the role of the putamen in processing positive affect in MDD, and the significance of its apparent disorderspecific dysfunctional activity.

It is of note that the current study extends our earlier finding of reduced right orbitofrontal activity upon reward outcome for OCD patients compared with controls (Remijnse et al. 2006), by showing that reward-associated blunted right medial OFC responsiveness uniquely dissociated OCD from both depressed (see Table 3) and healthy individuals (Appen$\operatorname{dix} B)$.

The neural correlates of affective switching have previously been localized both in (para)limbic brain regions (Cools et al. 2002; Remijnse et al. 2005a) and in areas involved in cognitive demands, that is the DLPFC and the anterior PFC (Remijnse et al. 2005a; Budhani et al. 2006; see also Appendix C). Of interest, the present experiment demonstrates a pattern of gradual decrease in DLPFC and anterior PFC activity during affective switching for healthy controls, MDD and OCD (Fig. 2). In addition, we found a diminished BOLD signal in the right insula and dorsal ACC in MDD patients relative to healthy controls. Our findings in the MDD group corroborate a recent fMRI study that reported in unmedicated depressed patients a failure to recruit the right ventrolateral PFC (using a region-of-interest analysis with a sphere that encompasses the area we designate as 'right insula') and the DLPFC (using a post-hoc whole-brain analysis), during affective switching (Taylor Tavares et al. 2008).
In MDD, decreased DLPFC and dorsal ACC metabolism and/or perfusion have frequently been observed in resting-state neuroimaging paradigms (Mayberg et al. 1994; Kennedy et al. 2001), and also in emotional (Bremner et al. 2007) and cognitive imaging activation designs (Okada et al. 2003; Siegle et al. 2007). Blunted activity in the DLPFC and dorsal ACC in MDD is generally considered the neural correlate of symptoms and psychological deficits in MDD, such as psychomotor retardation and executive impairments (Dolan et al. 1993; Rogers et al. 2004). In line with this interpretation, the diminished responsiveness of the DLPFC, anterior PFC and dorsal ACC during affective switching in MDD may reflect a reduced capacity for shifting a cognitive set and inhibiting the selection of a previously rewarded stimulus (Garavan et al. 2002; Smith et al. 2004). However, the present study did not show impaired behavioral performance during affective switching in depressed subjects. Therefore, the observed hyperactivity for MDD patients during affective switching in posterior (i.e. parietal) brain regions may be considered as compensatory recruitment for the relative failure to activate frontal areas. This converges with previous imaging activation studies that also reported increased parietal brain activity in MDD patients versus healthy subjects, in the presence of reduced ACC activation and equal task performance (Bremner et al. 2004, 2007).

The above-mentioned neuropathophysiological model of MDD (Phillips et al. 2003) posits that functional impairments in the DLPFC and dorsal ACC represent reduced effortful regulation of (negative) emotional states in this disorder. Again, our study is in agreement with this model by showing hypoactivity in these 'executive' brain regions upon a regulatory neuropsychological measure, that is affective switching.

Taken together, we suggest that the differential involvement of frontal-striatal and (para)limbic brain regions during reversal learning in MDD and OCD, as observed in the present study, may represent the neural correlates of biased emotional processing and reduced cognitive-behavioral flexibility in MDD and OCD. In addition, our findings in present and past papers (Remijnse et al. 2006) of distinct abnormalities in MDD and OCD seem to be in line with currently influential neurobiological models of these disorders. For OCD, the attenuated responsiveness in OFCstriatal and ACC structures during reward and affective switching events converge with the hypothesis of a dysfunctional (lateral) orbitofrontal loop as a key neurobiological underpinning of clinical and cognitive-behavioral manifestations of OCD (Chamberlain et al. 2005). Similarly, for MDD, the current results of increased insular but decreased dorsal ACC, DLPFC 
and anterior prefrontal cortical activity lend support to the proposed limbic-cortical ('ventral-dorsal') dysbalance as a core feature of this disorder (Mayberg, 1997, 2003).

The present study is not without limitations. First, the MDD group differed significantly from the other two groups with regard to the male/female ratio. We know of no previously described direct relationship between gender and the neural substrate of reversal learning, but sex differences may exist with regard to the human 5-HT system (Jans et al. 2007). As outlined in the introduction, reversal learning is dependent on normal 5-HT neurotransmission, and both MDD and OCD have been associated with a dysfunctional serotonergic system. Therefore, we cannot rule out that group interaction neural effects on reversal learning may have been mediated by differential betweengroup 5-HT system functioning due to an inverse gender ratio. Second, although the OCD group was free of currently co-morbid MDD, these patients scored significantly higher on depression severity measures than the healthy controls. However, the ratings in our OCD sample were well below consensusand computation-based cutoff scores for clinical remission in MDD, that is $<7$ for the HAMD-17 (Frank et al. 1991) and <10 for the MADRS (Zimmerman et al. 2004). In addition, a large and significant gap remained between OCD and MDD patients on all depression severity scores in this study.

In conclusion, our study shows differential frontalstriatal and paralimbic activity during reward, punishment and affective switching in unmedicated patients with either MDD or OCD compared with healthy controls. It would be of interest if future studies in MDD and OCD could further differentiate between cognitive and emotional aspects of these aberrant brain activations during reversal learning, for example by directly comparing BOLD responses during affective as opposed to cognitive switching behavior.

\section{Acknowledgments}

This work was supported by a TOP grant (no. 912-02050) and a grant (no. 907-00-012) from the Dutch Organization for Scientific Research (ZonMW-NWO).

\section{Declaration of Interest}

None.

\section{References}

Alexander GE, Crutcher MD, DeLong MR (1990). Basal ganglia-thalamocortical circuits: parallel substrates for motor, oculomotor, 'prefrontal' and 'limbic' functions. Progress in Brain Research 85, 119-146.
Anand A, Li Y, Wang Y, Wu J, Gao S, Bukhari L, Mathews VP, Kalnin A, Lowe MJ (2005). Activity and connectivity of brain mood regulating circuit in depression: a functional magnetic resonance study. Biological Psychiatry 57, 1079-1088.

APA (1994). Diagnostic and Statistical Manual of Mental Disorders, 4th edn. American Psychiatric Association: Washington, DC.

Beck AT (1963). Thinking and depression. I. Idiosyncratic content and cognitive disorders. Archives of General Psychiatry 9, 36-45.

Beck AT, Ward CH, Mendeson M, Mock J, Arbough J (1961). An inventory for measuring depression. Archives of General Psychiatry 4, 53-63.

Bremner JD, Vythilingam M, Vermetten E, Charney DS (2007). Effects of antidepressant treatment on neural correlates of emotional and neutral declarative verbal memory in depression. Journal of Affective Disorders 101, 99-111.

Bremner JD, Vythilingam M, Vermetten E, Vaccarino V, Charney DS (2004). Deficits in hippocampal and anterior cingulate functioning during verbal declarative memory encoding in midlife major depression. American Journal of Psychiatry 161, 637-645.

Budhani S, Marsh AA, Pine DS, Blair RJR (2006). Neural correlates of response reversal: considering acquisition. NeuroImage 34, 1754-1765.

Chamberlain SR, Blackwell AD, Fineberg NA, Robbins TW, Sahakian BJ (2005). The neuropsychology of obsessive compulsive disorder: the importance of failures in cognitive and behavioral inhibition as candidate endophenotypic markers. Neuroscience and Biobehavioral Reviews 293, 399-419.

Chamberlain SR, Müller U, Blackwell AD, Clark L, Robbins TW, Sahakian BJ (2006). Neurochemical modulation of response inhibition and probabilistic learning in humans. Science 311, 861-863.

Chamberlain SR, Sahakian BJ (2006). The neuropsychology of mood disorders. Current Psychiatry Reports 8, 458-463.

Clark L, Cools R, Robbins TW (2004). The neuropsychology of ventral prefrontal cortex: decision-making and reversal learning. Brain and Cognition 55, 41-53.

Cools R, Clark L, Owen AM, Robbins TW (2002). Defining the neural mechanisms of probabilistic reversal learning using event-related functional magnetic resonance imaging. Journal of Neuroscience 22, 4563-4567.

Deichmann R, Gottfried JA, Hutton C, Turner R (2003). Optimized EPI for fMRI studies of the orbitofrontal cortex. NeuroImage 19, 430-441.

Dias R, Robbins TW, Roberts AC (1996). Dissociation in prefrontal cortex of affective and attentional shifts. Nature 380, 69-72.

Dolan RJ, Bench CJ, Liddle PF, Friston KJ, Frith CD, Grasby PM, Frackowiak RSJ (1993). Dorsolateral prefrontal cortex dysfunction in the major psychoses: symptom or disease specificity? Journal of Neurology, Neurosurgery and Psychiatry 56, 1290-1294.

Drevets WC (2000). Neuroimaging studies of mood disorders. Biological Psychiatry 48, 813-829. 
Edmonstone Y, Austin MP, Prentice N, Dougall N, Freeman CPL, Ebmeier KP, Goodwin GM (1994). Uptake of ${ }^{99 \mathrm{~m}} \mathrm{Tc}$ exametazime shown by single photon emission computed tomography in obsessive-compulsive disorder compared with major depression and normal controls. Acta Psychiatrica Scandinavica 90, 298-303.

Elliott R, Sahakian BJ, McKay AP, Herrod JJ, Robbins TW, Paykel ES (1996). Neuropsychological impairments in unipolar depression: the influence of perceived failure on subsequent performance. Psychological Medicine 26, 975-989.

Epstein J, Pan H, Kocsis JH, Yang Y, Butler T, Chusid J, Hochberg H, Murrough J, Strohmayer E, Stern E, Silbersweig DA (2006). Lack of ventral striatal response to positive stimuli in depressed versus normal subjects. American Journal of Psychiatry 163, 1784-1790.

Evers EAT, Cools R, Clark L, van der Veen FM, Jolles J, Sahakian BJ, Robbins TW (2005). Serotonergic modulation of prefrontal cortex during negative feedback in probabilistic reversal learning. Neuropsychopharmacology 30, 1138-1147.

Fellows LF, Farah MJ (2003). Ventromedial frontal cortex mediates affective shifting in humans: evidence from a reversal learning paradigm. Brain 126, 1830-1837.

First MB, Spitzer RL, Gibbon M, Williams JBW (1996). Structured Clinical Interview for DSM-IV Axis I DisordersPatient Edition (SCID-1/P, Version 2.0). Biometrics Research Department, New York State Psychiatric Institute: New York.

Frank E, Prien RF, Jarrett RB, Keller MB, Kupfer DJ, Lavori PW, Rush AJ, Weissman MM (1991). Conceptualization and rationale for consensus definitions of terms in major depressive disorder. Remission, recovery, relapse, and recurrence. Archives of General Psychiatry 48, 851-855.

Fu CHY, Williams SCR, Cleare AJ, Brammer MJ, Walsh ND, Kim J, Andrew CM, Pich EM, Williams PM, Reed LJ, Mitterschiffthaler MT, Suckling J, Bullmore ET (2004). Attenuation of the neural response to sad faces in major depression by antidepressant treatment. A prospective, event-related functional magnetic resonance imaging study. Archives of General Psychiatry 61, 877-889.

Garavan H, Ross TJ, Murphy K, Roche RAP, Stein EA (2002). Dissociable executive functions in the dynamic control of behavior: inhibition, error detection, and correction. NeuroImage 17, 1820-1829.

Genovese CR, Lazar NA, Nichols T (2002). Thresholding of statistical maps in functional neuroimaging using the false discovery rate. NeuroImage 15, 870-878.

Goodman WK, Price LH, Rasmussen SA, Mazure C, Fleischmann RL, Hill CL, Heninger GR, Charney DS (1989). The Yale-Brown Obsessive Compulsive Scale. I: Development, use, and reliability. Archives of General Psychiatry 46, 1006-1011.

Hamilton M (1959). The assessment of anxiety states by rating. British Journal of Medical Psychology 32, 50-55.

Hamilton M (1967). Development of a rating scale of primary depressive illness. British Journal of Social and Clinical Psychology 6, 278-296.

Haruno M, Kawato M (2006). Different neural correlates of reward expectation and reward expectation error in the putamen and caudate nucleus during stimulus-actionreward association learning. Journal of Neurophysiology 95, 948-959.

Henriques JB, Glowacki JM, Davidson RJ (1994). Reward fails to alter response bias in depression. Journal of Abnormal Psychology 103, 460-466.

Jans LAW, Riedel WJ, Markus CR, Blokland A (2007). Serotonergic vulnerability and depression: assumptions, experimental evidence and implications. Molecular Psychiatry 12, 522-543.

Joel D, Zohar O, Afek M, Hermesh H, Lerner L, Kuperman R, Gross-Isseroff R, Weizman A, Inzelberg R (2005). Impaired procedural learning in obsessive-compulsive disorder and Parkinson's disease, but not in major depressive disorder. Behavioural Brain Research 157, 253-263.

Kalb R, Dorner M, Kalb S (2006). Opposite effects of depression and antidepressants on processing speed and error rate. Progress in Neuro-Psychopharmacology and Biological Psychiatry 30, 244-250.

Keedwell PA, Andrew C, Williams SCR, Brammer MJ, Phillips ML (2005). A double dissociation of ventromedial prefrontal cortical responses to sad and happy stimuli in depressed and healthy individuals. Biological Psychiatry 58, 495-503.

Kennedy SH, Evans KR, Krüger S, Mayberg SH, Meyer JH, McCann S, Arifuzzman AI, Houle S, Vaccarino FJ (2001). Changes in regional brain glucose metabolism measured with positron emission tomography after paroxetine treatment of major depression. American Journal of Psychiatry 158, 899-905.

Kumari V, Mitterschiffthaler MT, Teasdale JD, Malhi GS, Brown RG, Giampietro V, Brammer MJ, Poon L, Simmons A, Williams SCR, Checkley SA, Sharma T (2003). Neural abnormalities during cognitive generation of affect in treatment-resistant depression. Biological Psychiatry 54, 777-791.

Levine J, Cole DP, Roy Chengappa KN, Gershon S (2001). Anxiety disorders and major depression, together or apart. Depression and Anxiety 14, 94-104.

Mann JJ, Malone KM, Diehl DJ, Perel J, Cooper TB, Mintun MA (1996). Demonstration in vivo of reduced serotonin responsivity in the brain of untreated depressed patients. American Journal of Psychiatry 153, 174-182.

Mayberg HS (1997). Limbic-cortical dysregulation: a proposed model of depression. Journal of Neuropsychiatry and Clinical Neurosciences 9, 471-481.

Mayberg HS (2003). Modulating dysfunctional limbiccortical circuits in depression: towards development of brain-based algorithms for diagnosis and optimised treatment. British Medical Bulletin 65, 193-207.

Mayberg HS, Lewis PJ, Regenold W, Wagner Jr. HN (1994). Paralimbic hypoperfusion in unipolar depression. Journal of Nuclear Medicine 35, 929-934.

Mitterschiffthaler MT, Ettinger U, Mehta MA, Mataix-Cols D, Williams SCR (2006). Applications of functional magnetic resonance imaging in psychiatry. Journal of Magnetic Resonance Imaging 23, 851-861.

Mitterschiffthaler MT, Kumari V, Malhi GS, Brown RG, Giampietro VP, Brammer MJ, Suckling J, Poon L, 
Simmons A, Andrew C, Sharma T (2003). Neural response to pleasant stimuli in anhedonia: an fMRI study. Neuroreport 14, 177-182.

Montgomery SA, Asberg M (1979). A new depression scale designed to be sensitive to change. British Journal of Psychiatry 134, 382-389.

Murphy FC, Michael A, Robbins TW, Sahakian BJ (2003). Neuropsychological impairment in patients with major depressive disorder: the effects of feedback on task performance. Psychological Medicine 33, 455-467.

Murphy FC, Sahakian BJ, Rubinsztein JS, Michael A, Rogers RD, Robbins TW, Paykel ES (1999). Emotional bias and inhibitory control processes in mania and depression. Psychological Medicine 29, 1307-1321.

Murphy FC, Smith KA, Cowen PJ, Robbins TW, Sahakian BJ (2002). The effects of tryptophan depletion on cognitive and affective processing in healthy volunteers.

Psychopharmacology 163, 42-53.

Must A, Szabó Z, Bódi N, Szász A, Janka Z, Kéri S (2006). Sensitivity to reward and punishment and the prefrontal cortex in major depression. Journal of Affective Disorders $\mathbf{9 0}$, 209-215.

Ninan PT, Berger J (2001). Symptomatic and syndromal anxiety and depression. Depression and Anxiety 14, 79-85.

Okada G, Okamoto Y, Morinobu S, Yamawaki S, Yokota N (2003). Attenuated left prefrontal activation during a verbal fluency task in patients with depression. Neuropsychobiology 47, 21-26.

Overbeek T, Schruers K, Vermetten E, Griez E (2002). Comorbidity of obsessive-compulsive disorder and depression: prevalence, symptom severity, and treatment effect. Journal of Clinical Psychiatry 63, 1106-1112.

Phillips ML, Drevets WC, Rauch SL, Lane R (2003). Neurobiology of emotion perception. II: Implications for major psychiatric disorders. Biological Psychiatry 54, 515-528.

Purcell R, Maruff P, Kyrios M, Pantelis C (1998). Neuropsychological deficits in obsessive-compulsive disorder. A comparison with unipolar depression, panic disorder, and normal controls. Archives of General Psychiatry $55,415-423$

Remijnse PL, Nielen MMA, Uylings HBM, Veltman DJ $(2005 a)$. Neural correlates of a reversal learning task with an affectively neutral baseline: an event-related fMRI study. Neurolmage 26, 609-618.

Remijnse PL, Nielen MMA, van Balkom AJLM, Cath DC, van Oppen P, Uylings HBM, Veltman DJ (2006). Reduced orbitofrontal-striatal activity on a reversal learning task in obsessive-compulsive disorder. Archives of General Psychiatry 63, 1225-1236.

Remijnse PL, van den Heuvel OA, Veltman DJ (2005b). Neuroimaging in obsessive-compulsive disorder. Current Medical Imaging Reviews 1, 331-351.

Rogers RD, Blackshaw AJ, Middleton HC, Matthews K, Hawtin K, Crowley C, Hopwood A, Wallace C, Deakin JFW, Sahakian BJ, Robbins TW (1999). Tryptophan depletion impairs stimulus-reward learning while methylphenidate disrupts attentional control in healthy young adults: implications for the monoaminergic basis of impulsive behaviour. Psychopharmacology 146, 482-491.

Rogers MA, Kasai K, Koji M, Fukuda R, Iwanami A, Nakagome K, Fukuda M, Kato N (2004). Executive and prefrontal dysfunction in unipolar depression: a review of neuropsychological and imaging evidence. Neuroscience Research 50, 1-11.

Rolls ET (1999). The functions of the orbitofrontal cortex. Neurocase 5, 301-312.

Roth RM, Baribeau J, Milovan DL, O'Connor K (2004). Speed and accuracy on tests of executive function in obsessive-compulsive disorder. Brain and Cognition 54, 263-265.

Sanavio E (1988). Obsessions and compulsions: the Padua Inventory. Behaviour Research and Therapy 26, 169-177.

Saxena S, Brody AL, Ho ML, Alborzian S, Ho MK, Maidment KM, Huang SC, Wu HM, Au SC, Baxter Jr. LR (2001). Cerebral metabolism in major depression and obsessive-compulsive disorder occurring separately and concurrently. Biological Psychiatry 50, 159-170.

Siegle GJ, Thompson W, Carter CS, Steinhauer SR, Thase ME (2007). Increased amygdala and decreased dorsolateral prefrontal BOLD responses in unipolar depression: related and independent features. Biological Psychiatry 61, 198-209.

Smith AB, Taylor E, Brammer M, Rubia K (2004). Neural correlates of switching set as measured in fast, event-related functional magnetic resonance imaging. Human Brain Mapping 21, 247-256.

Smith KA, Fairburn CG, Cowen PJ (1997). Relapse of depression after rapid depletion of tryptophan. Lancet 349, 915-919.

Surguladze S, Brammer MJ, Keedwell P, Giampietro V, Young AW, Travis MJ, Williams SCR, Phillips ML (2005). A differential pattern of neural response toward sad versus happy facial expressions in major depressive disorder. Biological Psychiatry 57, 201-209.

Taylor Tavares JV, Clark L, Furey ML, Williams GB, Sahakian BJ, Drevets WC (2008). Neural basis of abnormal response to negative feedback in unmedicated mood disorders. NeuroImage 42, 1118-1126.

van Oppen P, Hoekstra RJ, Emmelkamp PM (1995). The structure of obsessive-compulsive symptoms. Behaviour Research and Therapy 331, 15-23.

Zimmerman M, Posternak MA, Chelminski I (2004). Derivation of a definition of remission on the Montgomery-Asberg depression rating scale corresponding to the definition of remission on the Hamilton rating scale for depression. Journal of Psychiatric Research 38, 577-582. 


\section{Appendix A}

'Glass brain' renderings showing task main effects and also group main effects for reward, punishment and affective switching. Overall, healthy control subjects showed more activations on reward and affective switching than patient group subjects,

whereas activations on punishment were roughly equal across groups. Importantly, not all apparent between-group differences reached statistical significance. See text and tables for details.
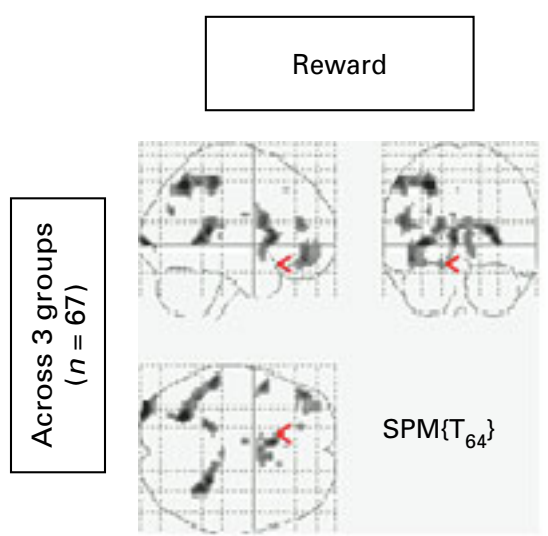

$\operatorname{SPM}\left\{\mathrm{T}_{64}\right\}$
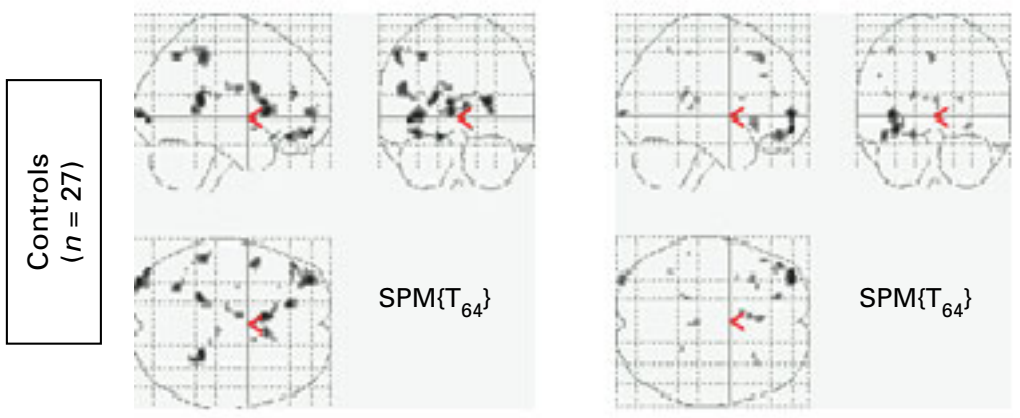

$\operatorname{SPM}\left\{T_{64}\right\}$

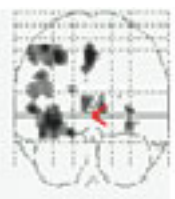

$\operatorname{SPM}\left\{T_{64}\right\}$
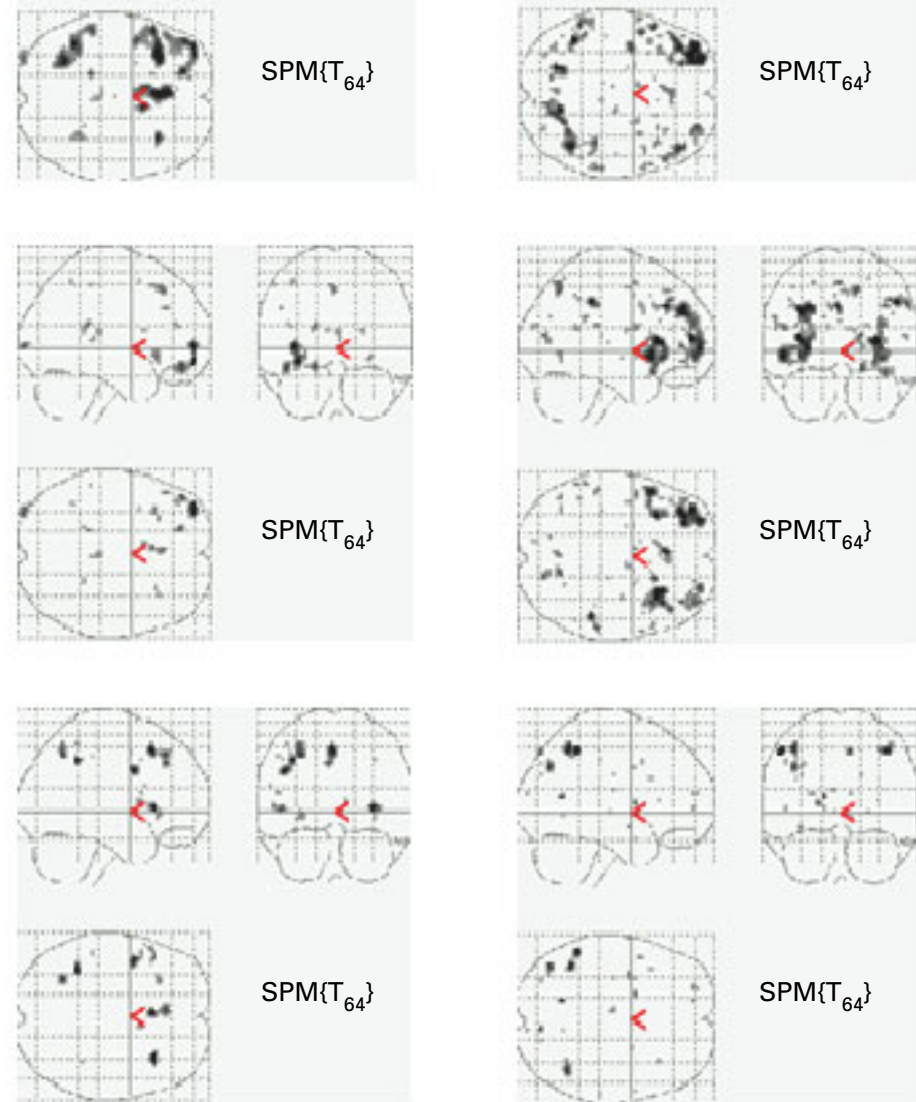

$\operatorname{SPM}\left\{\mathrm{T}_{64}\right\}$

$\operatorname{SPM}\left\{\mathrm{T}_{64}\right\}$
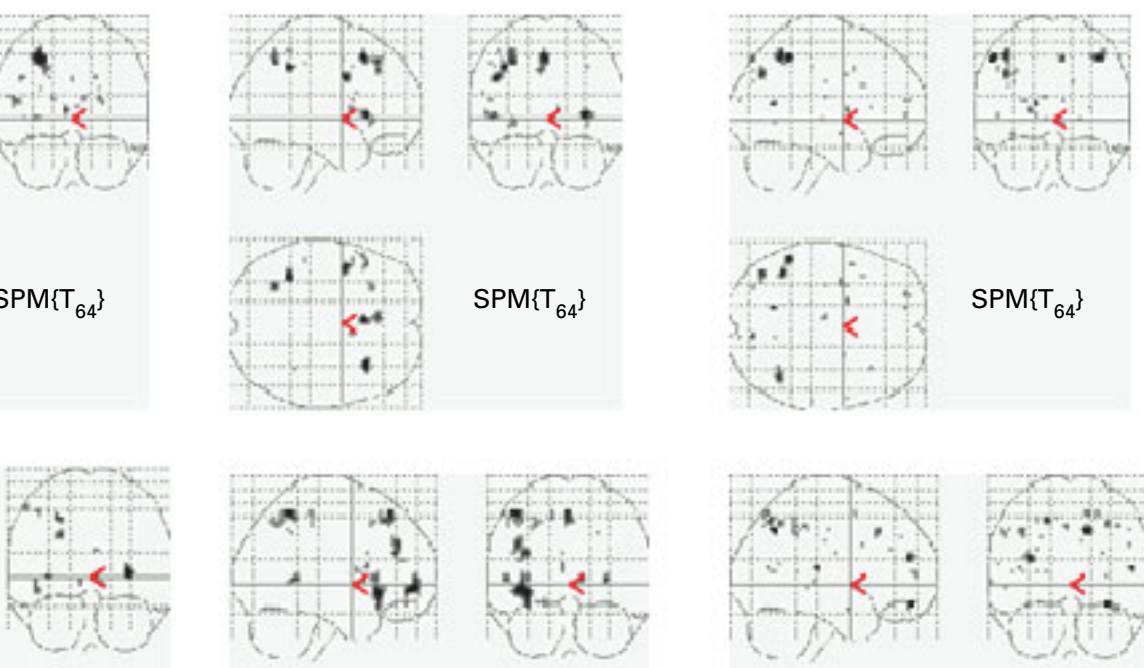

$\operatorname{SPM}\left\{\mathrm{T}_{64}\right\}$
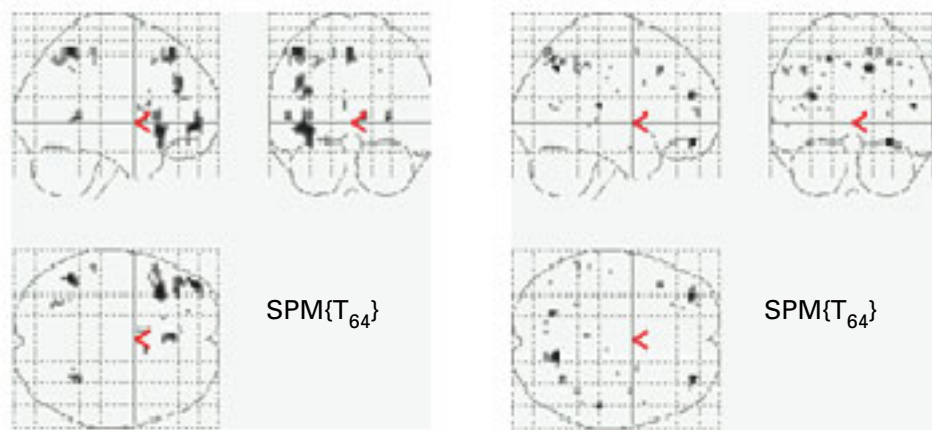

$\operatorname{SPM}\left\{\mathrm{T}_{64}\right\}$

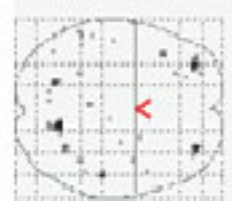

$\operatorname{SPM}\left\{\mathrm{T}_{64}\right\}$ 
Appendix B. Brain regions showing interaction effects for the obsessive-compulsive disorder $(O C D)$ versus healthy control group on reward, punishment and affective switching

\begin{tabular}{|c|c|c|c|c|c|c|c|c|c|c|c|c|}
\hline \multirow[t]{3}{*}{ OCD versus con } & \multirow[b]{3}{*}{$\mathrm{L} / \mathrm{R}$} & \multicolumn{4}{|c|}{ Reward } & \multicolumn{3}{|l|}{ Punishment } & \multicolumn{4}{|c|}{ Affective switching } \\
\hline & & \multicolumn{3}{|c|}{ MNI coordinates } & \multirow[b]{2}{*}{$z$ value } & \multicolumn{2}{|c|}{ MNI coordinates } & \multirow[b]{2}{*}{$z$ value } & \multicolumn{3}{|c|}{ MNI coordinates } & \multirow[b]{2}{*}{$z$ value } \\
\hline & & $\mathrm{x}$ & $\mathrm{y}$ & $\mathrm{z}$ & & $\mathrm{y}$ & $\mathrm{z}$ & & $\mathrm{x}$ & $\mathrm{y}$ & $\mathrm{z}$ & \\
\hline & & \multicolumn{4}{|c|}{ Controls $>$ OCD } & Controls $>$ OC & & & \multicolumn{4}{|c|}{ Controls $>$ OCD } \\
\hline Lateral OFC & $\mathrm{R}$ & 36 & 54 & -12 & $2.98^{*}$ & No significant & ons & & & & & \\
\hline Medial OFC & $\mathrm{R}$ & 15 & 36 & -15 & 3.70 & & & & & & & \\
\hline Posterior OFC & $\mathrm{L}$ & & & & & & & & -18 & 15 & -15 & 3.28 \\
\hline $\begin{array}{l}\text { Gyrus temporalis } \\
\text { superior }\end{array}$ & $\mathrm{R}$ & & & & & & & & 54 & -51 & 21 & 3.58 \\
\hline Parietal inferior & $\mathrm{R}$ & & & & & & & & 54 & -36 & 30 & 3.57 \\
\hline \multirow[t]{4}{*}{ Insular cortex } & $\mathrm{L}$ & & & & & & & & -30 & 21 & 9 & 5.08 \\
\hline & $\mathrm{L}$ & & & & & & & & -36 & 15 & 9 & 4.24 \\
\hline & $\mathrm{L}$ & & & & & & & & -36 & 27 & -6 & 3.78 \\
\hline & $\mathrm{R}$ & & & & & & & & 33 & 18 & 12 & 3.35 \\
\hline Anterior PFC & $\mathrm{L}$ & & & & & & & & -27 & 60 & 9 & 3.34 \\
\hline Dorsolateral PFC & $\mathrm{R}$ & & & & & & & & 48 & 3 & 18 & 3.47 \\
\hline \multirow[t]{2}{*}{ Anterior Cingulate } & $\mathrm{L}$ & & & & & & & & -6 & 36 & 18 & 3.84 \\
\hline & & & & & & & & & \multicolumn{4}{|c|}{ OCD $>$ Controls } \\
\hline Cuneus & $\mathrm{L}$ & -30 & -87 & 0 & 3.53 & OCD $>$ Contro & & & & & & \\
\hline $\begin{array}{l}\text { Temporal medius } \\
\text { cortex }\end{array}$ & $\mathrm{R}$ & & & & & No significant & ons & & 60 & -60 & 15 & 3.11 \\
\hline \multirow[t]{3}{*}{ Caudate } & $\mathrm{R}$ & 6 & 18 & 6 & $2.43^{*}$ & & & & & & & \\
\hline & & \multirow{2}{*}{\multicolumn{4}{|c|}{$\begin{array}{l}\mathrm{OCD}>\text { Controls } \\
\text { No significant activations }\end{array}$}} & & & & & & & \\
\hline & & & & & & & & & & & & \\
\hline
\end{tabular}

L, Left; R, right; MNI, Montreal Neurological Institute; OFC, orbitofrontal cortex; PFC, prefrontal cortex.

All activations at $p<0.001$ uncorrected, except for $z$ values* $(p<0.005)$. 
Appendix C. Task main effects collapsed across the three groups for reward, punishment and affective switching

\begin{tabular}{|c|c|c|c|c|c|c|c|c|c|c|c|c|c|}
\hline \multirow[b]{3}{*}{ Region } & \multirow[b]{3}{*}{$\mathrm{L} / \mathrm{R}$} & \multicolumn{4}{|c|}{ Reward } & \multicolumn{4}{|c|}{ Punishment } & \multicolumn{4}{|c|}{ Affective switching } \\
\hline & & \multicolumn{3}{|c|}{ MNI coordinates } & \multirow[b]{2}{*}{$z$ value } & \multicolumn{3}{|c|}{ MNI coordinates } & \multirow[b]{2}{*}{$z$ value } & \multicolumn{3}{|c|}{ MNI coordinates } & \multirow[b]{2}{*}{$z$ value } \\
\hline & & $x$ & $\mathrm{y}$ & $\mathrm{z}$ & & $x$ & $\mathrm{y}$ & $\mathrm{z}$ & & $x$ & $\mathrm{y}$ & $\mathrm{z}$ & \\
\hline \multirow[t]{2}{*}{ Lateral OFC } & $\mathrm{R}$ & 42 & 45 & -12 & 4.68 & 39 & 54 & -3 & 5.25 & & & & \\
\hline & & 33 & 51 & -15 & 3.01 & 33 & 57 & -9 & 5.04 & & & & \\
\hline Medial OFC & $\mathrm{R}$ & 18 & 42 & -12 & 4.03 & 21 & 45 & -15 & 5.15 & & & & \\
\hline Posterior OFC & $\mathrm{R}$ & 12 & 21 & -15 & 3.41 & 33 & 21 & -15 & 4.35 & & & & \\
\hline \multirow[t]{4}{*}{ Anterior PFC } & $\mathrm{R}$ & & & & & & & & & 36 & 54 & 9 & 4.92 \\
\hline & & & & & & & & & & 30 & 57 & 0 & 4.00 \\
\hline & & & & & & & & & & 27 & 51 & 18 & 4.74 \\
\hline & $\mathrm{L}$ & & & & & & & & & -27 & 57 & 3 & 3.61 \\
\hline \multirow[t]{4}{*}{ Dorsolateral PFC } & $\mathrm{R}$ & 45 & 42 & 18 & 4.50 & 42 & 42 & 30 & 4.01 & 48 & 6 & 39 & 3.64 \\
\hline & & & & & & 48 & 33 & 30 & 4.03 & & & & \\
\hline & $\mathrm{L}$ & & & & & & & & & -42 & 39 & 27 & 4.20 \\
\hline & & & & & & & & & & -42 & 45 & 33 & 4.10 \\
\hline Gyrus frontalis inferior & $\mathrm{R}$ & 51 & 9 & 21 & 4.70 & 45 & 3 & 30 & 4.56 & & & & \\
\hline \multirow[t]{2}{*}{ Dorsomedial PFC } & $\mathrm{R}$ & & & & & 3 & 27 & 48 & 5.69 & 3 & 27 & 36 & 3.69 \\
\hline & & & & & & 6 & 33 & 39 & 4.68 & & & & \\
\hline \multirow[t]{4}{*}{ Insular cortex } & $\mathrm{R}$ & & & & & 36 & 21 & -6 & 5.96 & 48 & 6 & 6 & 4.15 \\
\hline & & & & & & 51 & 18 & 3 & 5.13 & 33 & 27 & 3 & 3.64 \\
\hline & $\mathrm{L}$ & & & & & -33 & 21 & 3 & 4.86 & & & & \\
\hline & & & & & & -33 & 24 & 6 & 4.40 & & & & \\
\hline Temporal superior cortex & $\mathrm{R}$ & & & & & & & & & 57 & -48 & 18 & 3.68 \\
\hline \multirow[t]{3}{*}{ Parietal cortex superior } & $\mathrm{R}$ & 57 & -33 & 51 & 5.03 & & & & & 42 & -54 & 51 & 4.56 \\
\hline & & 42 & -48 & 51 & 4.52 & & & & & & & & \\
\hline & $\mathrm{L}$ & & & & & & & & & -42 & -57 & 48 & 4.75 \\
\hline \multirow[t]{2}{*}{ Parietal cortex inferior } & $\mathrm{R}$ & & & & & 30 & -60 & 45 & 5.40 & & & & \\
\hline & & & & & & 54 & -36 & 48 & 4.49 & & & & \\
\hline \multirow[t]{2}{*}{ Occipital cortex } & $\mathrm{R}$ & 33 & 96 & 0 & 6.33 & 30 & -96 & 0 & 4.32 & & & & \\
\hline & & 39 & -87 & -3 & 4.30 & & & & & & & & \\
\hline \multirow[t]{2}{*}{ Caudate nucleus } & $\mathrm{R}$ & 6 & 18 & 6 & 5.96 & 6 & 12 & 12 & 4.51 & & & & \\
\hline & $\mathrm{L}$ & -6 & 9 & 0 & 4.39 & -9 & 9 & 6 & 5.09 & & & & \\
\hline
\end{tabular}

L, Left; R, right; MNI, Montreal Neurological Institute; OFC, orbitofrontal cortex; PFC, prefrontal cortex.

All activations at $p<0.05$ false discovery rate (FDR)-corrected for multiple comparisons. 